\begin{tabular}{c} 
Volume and Issues Obtainable at Center for Sustainability Research and Consultancy \\
Journal of Business and Social Review in Emerging Economies \\
ISSN: 2519-089X (E): 2519-0326 \\
Volume 3: Issue 2December 2017 \\
CSRᄃ \\
Journal homepage: $\underline{\text { www.publishing.globalcsrc.org/jbsee }}$ \\
\hline
\end{tabular}

\title{
Overcoming Workplace Challenges: A Qualitative Study of Resilience Factors of Indonesian Women Factory Workers in Malaysia
}

\author{
${ }^{1}$ Ellys JuwitaPurba, ${ }^{2}$ Syed Mohamad Syed Abdullah \\ ${ }^{1,2}$ School of Education Studies, UniversitiSains Malaysia, 11800 USM, Pulau Pinang, Malaysia.
}

\section{ARTICLEDETAILS}

\section{History}

Revised format: Nov 2017

AvailableOnline: Dec 2017

\section{Keywords}

Workplaces Challenges,

Resilience,

Indonesian Women Factory

Worker

JEL Classification:

M54, M59

\begin{abstract}
Purpose: Aim to explore the experiences of Indonesian factory workers who perceived themselves as resilient individuals. This paper report the strategies used by Indonesian women factory workers to develop and maintain their resilience, despite encountering serious workplace challenges. Background Despite the potentially adverse effects of their quality of life such as psychological, social aspect thrive through exercising self-efficacy and coping skills. Resilience refers to the ability to cope well with challenges and change. Methodology: The method of this study is collective case study investigation of personal resilience from 20 Indonesian women factory workers. Interview transcripts were analyzed thematically.

Results: Indonesian women factory workers attributed their ability to succeed in the workplace to four major influences: Spiritual aspect, Social support, personal competence, Job environment Implication: Conclusively, Indonesian women factory workers' resilience ability insights contributed to a deeper understanding of personal resilience and highlight future initiatives to enhance the ability, skill and performance of factory workers in their workplace.
\end{abstract}

(C) 2017 The authors, under a Creative Commons AttributionNonCommercial 4.0

Corresponding author's email address: p.ellys@yahoo.com

Recommended citation:Purba,E.J. \& Abdullah,S.M.S., (2017) Overcoming Workplace Challenges: A Qualitative Study of Resilience Factors of Indonesian Women Factory Workers in Malaysia. Journal of Business and Social Review in Emerging Economies, 3(2) 169-178.DOI:https://doi.org/10.26710/jbsee.v3i2.188

\section{Introduction}

Malaysia has the highest migrant workers number in Southeast Asia, representing approximately $20 \%$ of the country's labour force (Malaysia Digest, 2015). At present, it has 2.9 million recognized and almost another 3 million unrecognized workers (Malaysia Digest, 2015), with the bulk of the worker from Indonesia, it was established that Indonesia has 50.9\%, of the total migrant populace (Ahmad, 2012). This indicates that 1 in 3 of the workers in Malaysia are migrants(Robertson \& Association, 2009). Indonesian women migrant workers have been a vital part of Malaysia's foreign migrant force for several decades and there is every indication that migrant workers will continue to play an essential role in many sectors of the Malaysian economy, including manufacturing(Kaur, 2008). Women migrant workers constituted approximately one-third of all foreign workers in manufacturing and one-half of all workers in the service sector. As previously noted, in Malaysia's importantelectronics industry, there were around 300,000 migrant workers, of whom $70-80$ per cent was women (Yong, 2006, p. 31). Migrant factory workers contribute substantially to the welfare of their families back home as well as to the city's 
economy, however Study shows that they have high depression (Bhugra \& Ayonrinde, 2004; Mou et al., 2011), this may be due to social stigma stereotyping, separation, status loss, discrimination, unfair treatment, and exclusion. These may also be source of their stressors(L. Li et al., 2007). All of these factors may contribute to their mental health problems. However Some Indonesian women factory worker have resilience to overcome challenges in Malaysia.

\subsection{Aim}

This study is to explore the experiences of Indonesian women factory workers who perceived themselves as resilient individuals. This paper report the strategies used by Indonesian women factory workers to develop and maintain their resilience in spite of challenges and changes.

\section{Literature Review}

Although, migrant factory workers contribute significantly to the welfare of their families back home as well as to the city's economy, however Study shows that they have high depression (Bhugra \& Ayonrinde, 2004; Mou et al., 2011), due to social stigma stereotyping, separation, status loss, discrimination, unfair treatment, and exclusion(L. Li et al., 2007). In contrast, other studies have revealed that women migrant workers may benefit from migration, with advantages such as greater autonomy, freedom from the oppression of rural patriarchy and greater exposure to modern living (Wong, He, Leung, Lau, \& Chang, 2008). Indonesian women factory workers face significant challenges, due to the character of institutions, and women's difficulties in adopting and internalizing the notion of 'empowerment'(Miles, 2016). Malaysia is one of the most export-dependent economies globally, one which is heavily reliant on women migrant workers, yet women possess limited prospects for moving up the occupational ladder or improving their economic position (Wye \& Ismail, 2012). There are some advantages to hire Migrant factory workers such as easily fired when firms want to cut back on their labour force, and easily re-hired when firms want to expand again", low payment compare to local factory workers . All these bring Migrant factory workers insecure in their workplace. Most of the women factory workers have come purposely to come and work so as to pay back their family debt due to the crumbling economy back in their country, Indonesia. They claimed they are motivated to work in Malaysia to support their families back home as well as to seek a better life for them. The difference in wages between Malaysia and Indonesia is large; the official estimate say that wages in Malaysia are up to three times higher than in Indonesia, (National wages and productivity commission 2014). Indonesian women factory workers have many challenges in the workplace, in relation to women's housing and health, and their interactions with locals, Moreover they are associated with the rise of sexual and moral problems (Hamidi, 2016)

Workplace challenges can be viewed as any nerve-wracking, negative, stressful, or difficult condition or occurrence of adversity that is faced in the occupational scenery. As Indonesian Women factory workers have multifaceted trials in their workplace like challenges as women migrant workers and the nature of their job as well. Work-related stress in factory included measures of job type (production or office), overtime, night work, exhaustion, job security, sick days, and a composite score of job strain. Working conditions are keys to understanding psychological well-being of workers who are frequently exposed to hazardous environment. Both physical and psychosocial work environment are important. According to previous studies, shift work, long work hours, hazardous work environment (e.g., exposure to noise or toxic chemicals) might be potential risk factors for poor mental health of the Chinese factory workers (X. $\mathrm{Li}$, Yang, \& Xu, 2006) Migrant workers in the factories have to work long hours - almost 12 hours per day and usually with overtime, including weekends. As many of them live in the factory premises, they have little time to get out and enjoy leisure time or a social life. A few may also experience sexual harassment and discrimination by their superiors in the factories (Wong et al., 2008; Wong \& Song, 2008). Furthermore mostly factory workers have limited physical activity; this can as well trigger depression in them (Liu et al., 2015).

Resilience is considered as self-motivated procedure incorporating encouraging adaptation in the context of noteworthy hardship (Luthar, Cicchetti, \& Becker, 2000). Mental resilience is expressed as the ability 
to move in an optimistic direction from the point of negativity, distressing or stressful experiences. Resilience results to flourish at place of work and cope with the changes by getting the problem solved (Tusaie \& Dyer, 2004). Individuals with good resilient ability responds to confrontational situations by identifying and admitting the influence, the time invested, the energy and the resources required to bounce back to equilibrium (Youssef \& Luthans, 2007). Furthermore, resilience afford an individual to make use of any obstacles as a springboards(Youssef \& Luthans, 2007), or at times, an opportunity to advance and develop. In another development, resilience play a substantial part in managing stresses that are positive and also, resilience might be characterized as a coping strategy to both adverse and positive events like promotions or new employment tasks or requirements. (Davidson \& Moss, 2011) argued that positive thinking and its core dimensions such as resilience are expedited whenever an individual possess a sincere involvement and enable environment in the work place. Strategies for self-growth can assist in developing personal resilience towards workplace challenges, most importantly, self-grounded challenges such as establishing positive cultivation professional relationship and networks, positivity maintenance, Emotional perception development, Attaining spiritual and life balance and achieving more reflective mood.

\section{Methods}

In this study, a case study approach and qualitative data collection methods were used to investigate the phenomenon in question. The research design was an instrumental collective case study, investigating particular cases. The study aimed to explore personal resilience through an instrument; examining the 'wholeness' of the specific case facilitated understandings.

Table 1 below outlines the demographic details of the 20 case study participants and potential factors responsible for their experience while working at a factory in Penang Malaysia. The respondents were subjected to psychological test using Connor Davidson resilience scale (CD-RISC) to see the level of resilience. For the test we selected 20 participants, out of which 10 have high resilience and 10 low resilience and already working above 2 years. After giving their conversant consent, the participants were interviewed at a convenient time and place. The interviews were designed to be semi-structured and conversational, covering topics from the participants' personal support networks, work environment, experiences of surviving and thriving in the workplace, understandings of resilience and their views on the resilience enhancement through professional development.

This paper report specifically on how the interplay of these factors that enhanced resilience are assessed qualitatively.In keeping with a qualitative, exploratory approach. The analysis was founded on a nonlinear procedure of understanding, synthesizing, hypothesizing and re-contextualizing the words of the participants into an authentic explanation of experiences. The process initiated with many readings of the transcripts, taking the memo of crucial ideas, experiences and opinions of participants. Thick description was used to form clear, eloquent clarifications of the phenomena being explored. Then main features of both individual and collective standpoints were incorporated to form themes.

\section{Results}

The study participants were aware of the negative effects their work caused to the health and well-being of their colleagues, and stated that they experienced similar problems themselves at several stages of their careers. Study participants were aged between 18 to 44 years; they have been working in Malaysia between 2-8 years. Out of 20 participants, 18 were single, one was widowed and one was the married. Socio-demographic characteristic of the participants are detailed in Table1.According to Connor Davison resilience scale (CD- RISC) 10 out of the 20 participants were having high resilience level and the rest has moderate level. Therefore, they are more productive and stronger by overcoming their everyday workplace challenges. 
Four major themes revealed how Indonesian women factory workers resolved the negative impact of workplace challenges, they are; Spiritual aspect, Social support, personal competence, Job environment (Table 2).

\section{Spiritual Aspects}

Religious activity---- spiritual relationship with God

Participants believe going to church regularly make their strength renew and recharge, therefore they always prioritize time for church. For example, one of the respondents believes that going to church regularly is her strength. In her words,

Every time I come back from church I feel my strength renewed and recharge again (Dona)

Some participants voluntarily engaged in some form of service at the church so they feel confidence and significant to others. One of them claims she improves her social skill from the church activities which is an important skill in her company. She claimed;

I learn to lead and serve others in my church. I feel confident when I relate to people in my company and significant because I can help others.

Religious activities have surpassed both the contexts and consequences of inequality as clearly demonstrated through association and serving with minimum stress, happiness, satisfaction, fulfillment, and renewal. Two of the respondents said that church provide them the properties of bonding to others ("to serve another family"), spiritual influence and reframing ("God is there for me"), and engagement in activities of high personal interest ("I love what I'm doing"):

When I get here in church, I am very happy, I forget my six working day rigors, time fly fast, I felt that it's a brand new day again when I go back to my house, because any time I come here to church, my stress is removed and I am renewed, I feel that I have so many friends here, that make you laugh, then have some fun together. (Yenny and Tri)

Gratitude

Gratitude is an expression of spiritual experiences of participants who gave thanks to God for protection over their lives, particularly for overcoming the hurdles as migrant workers. One of them feels thankful because she can survive work in Malaysia because of God's protection

I am so thankful to God because He always helps me to overcome my problem and difficulties. (Ida)

\section{Social support}

Social support factors were identified as being useful for improved personal resilience and flourishing within a possibly destructive workplace.

Family

The participants strongly believed that the family supports increased their ability to feel emotionally secure and sustain a positive self-concept when dealing with the negative events and conditions of their working lives. A respondent expressed the value she placed upon her Mother and her sisters who provided emotional and practical support:

I always talk to my Mother whenever I feel sad she always cheer me up. My Sisters also work here so I often visit them whenever I lonely. I feel so happy whenever I hang out with my sisters. (Sanny)

Participants shared accounts of hardships and happiness with family members. Distributing care across borders, they drew emotional strength from one another. One of the respondents expressed the value of her family to boost her energy anytime she has stress

I feel my energy booster when I talk to my family. So whenever I am down and tired I just call them. They are my strength (Franny)

Participants believe their family is motivation for working in Malaysia so difficulties and challenges will not make them stop. Desy's family relies on her therefore she must be strong

My family is very poor. So they relied and need me. If I am not working how can my family live?, so that is why I always say to myself I have to be strong (Desy).

Friends in the workplace

The blooming participants were very conscious of the role of friends support, believing it delivered the most significant benefit when facing trials or adverse outcomes at work, even more active than that of 
support from partners or close friends. These participants had built an atmosphere conducive for positive communication within their work environments.

One of the respondents felt her friends in the workplace are like family because they live and work together all the time. Another one said whenever she feels tired and inadequate her team helps her a lot. Meanwhile, another respondent experienced very difficult in the first year, but her friends trained her how to control the system. Signifying a depth of trust and confidence in the support of her colleagues:

I still remember the first year in my company I totally lost but thank God. My seniors help me to operate the engine. She was really kind and patient to teach me all things that I should know. (Yenny)

An important element of these supports was that colleagues shared skill, knowledge of the organizational hierarchies, issues that relate to the relationship dynamics within the department. These participants had built communal, helpful relationships with each other over years of working together, sharing similar experiences, especially as migrant workers in dealing with workplace challenges. They believed, because of these shared experiences, their colleagues could better understand their feelings and circumstances. One of them recounted her experience of finding resolution from feelings of guilt, shame and inadequate and the regaining of confidence in her skill to control the engine: In her words,

I was so panic because suddenly the engine stop and I am the only one in that system that time, then my leader came to settle the problem. I feel guilt, shame and feel really bad about it,' and then I'd think about it all day. Eventually, talking to my friend [colleagues], getting their positive feedback, reflecting on what happened, different ways of responding and how I can improve in the future, all these really help me to release my stress. (Kartika)

Participants enjoyed working processes and conditions which supported sustainable relationships at work; they were generally able to take meal breaks together, and they have same sifted worked regular hours, so it was easier to arrange opportunities for interaction and reciprocity, such as go with same bus. For Rosemary, having an approachable person in the hostel and her department was an essential part of feeling secure and satisfied in the job, and influenced her sense of belonging and not feel lonely:

[Her] door is always open if you're stressed, you can always knock on her door, sit down with my friend in her room and go through it. (Rosemary)

3. Personal competence

Personal competence factors associated with resilience were seen as vital to weathering the effects of workplace trials. Participants observed that their personal skills and resilient attributes which had developed over time contributed to their sense of competency and wellness. In addition, personal practices supporting holistic health and well-being, and self confirming beliefs about themselves and their ability to change situations to their advantage had helped them to persist, sometimes over long careers, despite persistent and potentially damaging problems with their workplace.

Self-care

Participants who felt they are flourished in the work environment show how they spent their free time such as rest, sports, do their hobbies and hang out with friends so that they can sidetrack worrying aspects of work. Participants believed that refreshing activities, such as sports, music, do their hobbies and hang out with friends were relaxing and helpful for dealing with workplace stress. One of them described listening to music and doing "Zumba" dance as her self-care strategies:

I just go home, put some music on and once a week during my day off I go with my friend for Zumba dance and then we go hang out. I feel so energetic whenever I do Zumba dance.(Corry)

Like Corry, group activities contributed to self-care for several participants. However, some participants found it useful to disengage completely from other people through activities such as sleeping and jogging and praying or having a regular day alone:

I like to be alone, especially when I have the day off. I like just to sleep whole day and jogging (Priska)

My prayer time is really energizing and charges me (Ida) 
Dream to have better education

Having a dream to have a better education is patterned and behaviors that are also beneficial in sustaining the participants. Lisma's dream is to be a teacher, which makes her diligent and committed to finish the contract time.

My goal helps me to finish my commitment, so that I can earn money as much as I needed for my further study. (Lisma)

Sarida and Desi believe working in factory is only for temporary, so whenever they have stresses in the workplace, they just remind themselves of their biggest dream

Every time I feel so sad and down, I always remind myself it's just two years after I can study in university.(sarida)

Working in factory is just a stepping stone for me because I really want to go to university. (desi)

\section{Job Environment}

Participants described job environment and their roles within the organization as a means of enhancing their resilience. They organized their work to emphasize the satisfying aspects, which helped them overcome the work-based difficulties they faced. These measures facilitated self recognition of their contribution in an atmosphere with little formal acknowledgement, instilling some intrinsic rewards of giving good salary and loan. Work became more personally rewarding with greater scope for leadership, decision-making and enjoyable challenges.

Good salary and loan (reward and benefit system)

Though life in Malaysia is hard, but I can earn much money as long as I am willing to work hard (Tamaria)

Though it is so stressful but it's worthy because I can see the fruit of my hard work (Idamanulang)

I am sorry to say this I can bear all the suffering only because the salary is good so that I can support my family(Lisma)

The teamwork in the factory

"I have been working with this factory for seven years. I really like my factory because the leader is good. My leader treats us equally and also he always give us reward if we achieve the targets. So it gives me motivation to work hard "

"I like my team, we are taking each other as one team, although we have so many jobs. I always have energy because I like my leader and my team"

"Our relationship with my team is like family because we share our burden together and also we have same suffering “

\section{Discussion}

For the participants in this study the most significant form of protection from workplace challenges was spiritual aspects. This coincides with the outcome of past study, Religious activities serving as "a context for building competencies in their members," in which the skills and talents of Indonesian women factory workers are recognized and developed (Hathaway \&Pargament, 1991, p. 84). Helping others might have increased participants' capacity to handle their own hardships (Lietz, 2011). More so, Spiritual activities were motivated by and involved for spiritual resolutions and meaning. Past research studies have a tendency to disregard the supreme nature of spirituality in favour of the social or organizational potentials of religion (Henery, 2003).

Social support contributes to improved resilience. This is in conjunction with earlier literature that recognizes friends as a significant component of workplace resilience (Jackson et al. 2007). In this study, the participants who believed they were prosperous had recognized mutual relationships which occasioned in helpful information being taken when desired, minimized stress in individuals and permitted productivity and effectiveness. Their social support enabled successful triangulation through the organizational hierarchy, which reduced the personal liability experienced and placed the participants 
for greater job satisfaction and probable career benefit. Their team work strengthened a sense of belonging which affected the positive approaches towards the workplace and kept their commitment to work alive. Social support can improve resilience level of Indonesian factory workers, this finding is in line with other studies. High value social support and family support was shown to be connected with increased resilience and lower levels of psychological glitches in all stages of the encounter-prompted mandatory migration(Siriwardhana, Ali, Roberts, \& Stewart, 2014)

Personal proficiency such as self-care and dream to achieve higher education also appeared as primary ways that Indonesian women factory workers help themselves uphold a sense of stability in challenging workplaces. Previous research proposed the advantages of workers in large scale organizations owning confidence and flexibility(Avey, Nimnicht, \& Graber Pigeon, 2010). Self-care and dream to have higher education appeared as the important factors for these Indonesian women factory workers, they may be measured as part of a variety of resilient personal features, including optimism, flexibility, toughness, passionate intuition and life balance (Jackson et al. 2007). Recent research has stretched the concept of self-care to more than temporary, gratifying happenings that divert from workplace stressors and enhancement energy levels(Richards, 2013). Reasonably, routine maintenance of physical and emotional health and well-being must be realized as crucial to personal and professional resilience. Work life balance practices may augment employee resilience (Wood \& de Menezes, 2010)

Job Environment in term of salary and Leadership contribute to augment the resilience of Indonesian women factory workers.Guaranteeing safer and healthy workplaces, offering better salary and benefits, providing higher job security and recurrent managerial interactions may slightly help moderate the dominance and problem of depression(Fitch et al., 2017)In other study, it is established that reward system and working condition can improved resilience(Cascio, 2012) The factors that influence their resilience are job demands, job deprivations, and job rewards, and by the work environment, both physical and social(Loscocco\& Spitze, 1990). In another related analyses of employee resilience, emphasis is placed on the behavior of managers and leaders (Luthans, 2002). Managers who understand workplace resilience can help employees acclimatize and survive workplace change (Siebert, 2006). While reasonably

little is acknowledged about the connection between leader behavior and employee resilience, the research stretched the importance of positivity displayed by leadership (Luthans, Norman, Avolio, \& Avey, 2008). Resilience can be advanced by means of various Human Resources Development (HRD) practices (Bardoel, Pettit, De Cieri, \& McMillan, 2014)

\section{Conclusion}

This study's findings indicated that Indonesian women factory workers are highly resilient able in the center of adversity, trials necessitating a strength-based tactic for practice(Sun, 2013; Wong \& Song, 2008). This goes to prove that they are able to withstand the rugged phases associated with migration, working in foreign land rigors without any sign of serious depression. The implication of this study is Indonesian women factory workers' resilience insights contributed to a deeper understanding of personal resilience and highlight future initiatives to enhance the ability, skill and performance of factory workers in their workplace. 
Table 1.Demography of Participants

\begin{tabular}{|c|c|c|c|c|c|c|}
\hline NO & NAME & AGE & $\begin{array}{l}\text { EDUC } \\
\text { ATION } \\
\end{array}$ & $\begin{array}{c}\text { MARITAL } \\
\text { STATUS }\end{array}$ & $\begin{array}{c}\text { TIME IN } \\
\text { MALAYSIA }\end{array}$ & $\begin{array}{c}\text { Resilience } \\
\text { Level }\end{array}$ \\
\hline 1 & SARTIKA LESTARI & 24 & SMA & SINGLE & 3 & High \\
\hline 2 & TRI PITRI INDAON & 21 & SMA & SINGLE & 3 & High \\
\hline 3 & YENNY NAIBAHO & 30 & D3 & SINGLE & 5 & High \\
\hline 4 & MURNI ANI & 23 & SMA & SINGLE & 3 & High \\
\hline 5 & CORRY RAHAYU & 19 & SMA & SINGLE & 8 & High \\
\hline 6 & YESUINA ASIH & 29 & SMA & SINGLE & 3 & High \\
\hline 7 & TAMARIA PONE & 44 & SMA & WIDOW & 6 & High \\
\hline 8 & PRISKA DAMANIK & 21 & SMA & MARIED & 2 & High \\
\hline 9 & IDA MANULIANG & 22 & SMA & SINGLE & 3 & High \\
\hline 10 & SARTIKA KARTINI & 22 & SMA & SINGLE & 2 & High \\
\hline 11 & LISMA & 20 & SMA & SINGLE & 2 & Moderate \\
\hline 12 & ROSEMERY & 28 & SMA & SINGLE & 6 & Moderate \\
\hline 13 & MERIANA & 18 & SMA & SINGLE & 2 & Moderate \\
\hline 14 & FRANNY & 25 & SMA & SINGLE & 3 & Moderate \\
\hline 15 & DONNA & 28 & SMA & SINGLE & 3 & Moderate \\
\hline 16 & SANNI & 28 & SMA & SINGLE & 3 & Moderate \\
\hline 17 & SARIDA & 26 & SMA & SINGLE & 3 & Moderate \\
\hline 18 & ELVINA & 27 & SMA & SINGLE & 7 & Moderate \\
\hline 19 & DINA & 22 & SMA & SINGLE & 3 & Moderate \\
\hline 20 & DESI & 24 & SMA & SINGLE & 5 & Moderate \\
\hline
\end{tabular}

Table 2. Resilience Factors Indonesian women factory workers

\begin{tabular}{lcll}
\hline Theme & Sub-theme & $\mathrm{N}=20$ \\
\hline Spiritual aspects & $\bullet$ & Active in Religious program & 20 \\
& $\bullet$ & Gratitude & 16 \\
\hline Social Supports & $\bullet$ & Family & 19 \\
& $\bullet$ & Friends in workplace & 15 \\
\hline Job environment & $\bullet$ & Good salary and loan & 18 \\
& $\bullet$ & Leadership and team work & 17 \\
\hline Personal competence & & \\
& $\bullet$ & Self care & 16 \\
& - & Dream to have better education & 15
\end{tabular}

References

Ahmad, L. (2012). Labour migration: Malaysia as a receiving country. 2nd ADBI-OECD roundtable on labour migration in Asia, Tokyo, Japan.

Avey, J. B., Nimnicht, J. L., \& Graber Pigeon, N. (2010). Two field studies examining the association between positive psychological capital and employee performance. Leadership \& Organization Development Journal, 31(5), 384-401.

Bardoel, E. A., Pettit, T. M., De Cieri, H., \& McMillan, L. (2014). Employee resilience: an emerging challenge for HRM. Asia Pacific Journal of Human Resources, 52(3), 279-297.

Bhugra, D., \& Ayonrinde, O. (2004). Depression in migrants and ethnic minorities (Vol. 10).

Cascio, W. F. (2012). How does downsizing come about. Downsizing: Is less still more, 51-75. 
Davidson, A. C., \& Moss, S. A. (2011). The negative side of positive thinking: Aresta.

Fitch, T. J., Moran, J., Villanueva, G., Sagiraju, H. K. R., Quadir, M. M., \& Alamgir, H. (2017).

Prevalence and risk factors of depression among garment workers in Bangladesh. International Journal of Social Psychiatry, 63(3), 244-254.

Hamidi, M. (2016). Indonesian female factory workers: the gendered Migration policy in malaysia. People: International Journal of Social Sciences, 2(1).

Kaur, A. (2008). International migration and governance in Malaysia: Policy and performance. UNEAC Asia Papers, 22, 4-18.

Li, L., Wang, H.-m., Ye, X.-j., Jiang, M.-m., Lou, Q.-y., \& Hesketh, T. (2007). The mental health status of Chinese rural-urban migrant workers. Social psychiatry and psychiatric epidemiology, 42(9), 716-722.

Li, X., Yang, S., \& Xu, S. (2006). Investigation of the Mental Health states of the workers in shifts. Med J Chinese People's Health, 18, 216-217.

Liu, J., Cheng, Y., Lau, J. T., Wu, A. M., Vincent, W., \& Zhou, S. (2015). The Majority of the Migrant Factory Workers of the Light Industry in Shenzhen, China May Be Physically Inactive. PloS one, 10(8), e0131734.

Loscocco, K. A., \& Spitze, G. (1990). Working conditions, social support, and the well-being of female and male factory workers. Journal of Health and Social Behavior, 313-327.

Luthans, F. (2002). Positive organizational behavior: Developing and managing psychological strengths. The Academy of Management Executive, 16(1), 57-72.

Luthans, F., Norman, S. M., Avolio, B. J., \& Avey, J. B. (2008). The mediating role of psychological capital in the supportive organizational climate-employee performance relationship. Journal of organizational behavior, 29(2), 219-238.

Luthar, S. S., Cicchetti, D., \& Becker, B. (2000). The construct of resilience: A critical evaluation and guidelines for future work. Child Development, 71(3), 543-562.

Miles, L. (2016). The Social Relations Approach, empowerment and women factory workers in Malaysia. Economic and Industrial Democracy, 37(1), 3-22.

Mou, J., Cheng, J., Griffiths, S. M., Wong, S., Hillier, S., \& Zhang, D. (2011). Internal migration and depressive symptoms among migrant factory workers in Shenzhen, China. Journal of Community Psychology, 39(2), 212-230.

Richards, K. (2013). Self-care is a lifelong journey. Nursing Economics, 31(4), 198.

Robertson, P. S., \& Association, F. L. (2009). Migrant Workers in Malaysia-Issues, Concerns and Points for Action.

Siebert, A. (2006). Strengthening workforce resiliency in the public sector. Public Manager, 35(3), 3.

Siriwardhana, C., Ali, S. S., Roberts, B., \& Stewart, R. (2014). A systematic review of resilience and mental health outcomes of conflict-driven adult forced migrants. Conflict and Health, 8(1), 13. doi: 10.1186/1752-1505-8-13

Sun, P. (2013). Transcending Inequality: A Grounded Theory Study of Filipino Factory Workers in Taiwan.

Tusaie, K., \& Dyer, J. (2004). Resilience: A historical review of the construct. Holistic nursing practice, $18(1), 3-10$.

Wong, D. F. K., He, X., Leung, G., Lau, Y., \& Chang, Y. (2008). Mental health of migrant workers in China: prevalence and correlates. Social psychiatry and psychiatric epidemiology, 43(6), 483-489.

Wong, D. F. K., \& Song, H. X. (2008). The resilience of migrant workers in Shanghai China: the roles of migration stress and meaning of migration. International Journal of Social Psychiatry, 54(2), 131143.

Wood, S. J., \& de Menezes, L. M. (2010). Family-friendly management, organizational performance and social legitimacy. The International Journal of Human Resource Management, 21(10), 15751597.

Wye, C.-K., \& Ismail, R. (2012). Labour market structure in Malaysia: Pre-and post-market gender 
comparison. International Journal of Academic Research in Business and Social Sciences, 2(10), 259.

Youssef, C. M., \&Luthans, F. (2007). Positive organizational behavior in the workplace: The impact of hope, optimism, and resilience. Journal of management, 33(5), 774-800. 